Research Paper

\title{
P Wave Dispersion and QT Dispersion in Adult Turkish Migrants with Familial Mediterranean Fever Living in Germany
}

\author{
Arnd Giese ${ }^{1,2}$, Ahmet Örnek²,3, Mustafa Kurucay², Kaffer Kara4, Helmut Wittkowski ${ }^{5,6}$, Faekah Gohar ${ }^{5,6}$, \\ Bjoern A. Menge ${ }^{1}$, Wolfgang E. Schmidt ${ }^{1}$, Christoph Zeidler ${ }^{1}$ \\ 1. Department of Internal Medicine I, St. Josef-Hospital, Medical Centre of the Ruhr-University Bochum, Gudrunstraße 56, 44791 Bochum, Germany \\ 2. Department of Internal Medicine I, Marienhospital Herne, Medical Centre of the Ruhr-University Bochum, Herne, Germany \\ 3. Institute for Radiologic Diagnostics, Bergmannsheil, Ruhr-University Bochum, Bochum, Germany \\ 4. Department of Internal Medicine II, St. Josef-Hospital, Medical Centre of the Ruhr-University Bochum, Bochum, Germany \\ 5. Department of Paediatric Rheumatology and Immunology, University Children's Hospital Muenster, Germany \\ 6. AID-NET Autoinflammatory disorders (AID) in children: Genetics, disease mechanisms, diagnostic markers and therapeutic targets, Essen and \\ Muenster, Germany
}

$\bowtie$ Corresponding author: Tel.: +49 234509 0; Fax: +49 234509 3589; Email: arnd.giese@rub.de

(c) Ivyspring International Publisher. This is an open-access article distributed under the terms of the Creative Commons License (http://creativecommons.org/ licenses/by-nc-nd/3.0/). Reproduction is permitted for personal, noncommercial use, provided that the article is in whole, unmodified, and properly cited.

Received: 2014.04.19; Accepted: 2014.07.21; Published: 2014.08.21

\begin{abstract}
Background: Familial Mediterranean Fever (FMF) is a hereditary autoinflammatory disease associated with subclinical inflammation, which includes atherosclerosis arising from endothelial inflammation, which in turn increases the risk of atrial or ventricular arrhythmias. Conduction abnormalities can be detected using the electrocardiographic (ECG) indices $\mathrm{P}$ and QT dispersion (Pdisp and QTdisp). Currently, it is unknown whether patients with FMF are more likely to have abnormalities of these ECG indices. Moreover, existing studies were conducted in countries with higher FMF prevalence. We therefore perform the first prospective study assessing Pdisp and QTdisp in adult FMF patients in Germany, where prevalence of FMF is low.
\end{abstract}

Method: Asymptomatic FMF patients $(n=30)$ of Turkish ancestry living in Germany and age-matched healthy controls $(n=37)$ were prospectively assessed using 12-lead ECG.

Results: Patients and controls were comparable in gender and body mass index, and patients had higher erythrocyte sedimentation rate (ESR), C-reactive protein (CRP) and serum amyloid $A$ (SAA) compared to controls (ESR: $23.7 \pm 14.3$ vs. $16.1 \pm 13,3 \mathrm{~mm} / \mathrm{I}^{\mathrm{st} h}, p=0.03$, CRP: $0.73 \pm 0.9$ vs. $0.26 \pm 0.4 \mathrm{~g} / \mathrm{dl}, \mathrm{p}=0.0 \mathrm{I}, \mathrm{SAA}: 3.14 \pm 4,8 \mathrm{vs}$. $0.37 \pm 0.3 \mathrm{mg} / \mathrm{dl}, \mathrm{p}<0.0 \mathrm{I})$. No statistically significant difference between patients and controls respectively, for $P$ disp $(43.7 \pm 11.9 \mathrm{vs} .47 .1 \pm 11.2 \mathrm{~ms}, p=0.23)$, QTdisp $(65.9 \pm 12.3$ vs. $67.6 \pm 12.7 \mathrm{~ms}, \mathrm{p}=0.58)$ or corrected QTdisp (cQTdisp: $73.9 \pm 15.0$ vs. $76.0 \pm 13.3 \mathrm{~ms}, p=0.55$ ) was found. No correlation could be found between Pdisp or QTdisp or cQTdisp and any of the biochemical markers of inflammation.

Conclusion: FMF patients living in Germany show a Pdisp and QTdisp comparable to healthy controls, with no increased risk of atrial or ventricular arrhythmias indicated.

Key words: Familial Mediterranean Fever; Turkish migrants; P dispersion; QT dispersion; Germany; Arrythmia risk

\section{Background}

Familial Mediterranean Fever (FMF) is a hereditary autoinflammatory disease characterized by unprovoked, self-limiting attacks of fever and serositis
(1), diagnosed using clinical criteria (2). It is associated with mutations in the MEFV-gene encoding for the pyrin protein $(3,4)$. Lifelong prophylactic administra- 
tion of colchicine is the therapy of choice $(5,6)$, which can reduce FMF attacks (7-9) and prevents the development of amyloidosis (10), the most severe long-term complication of FMF. However, subclinical inflammation may persist in clinically stable FMF patients (11).

As inflammatory processes underly the development of atherosclerosis, which can contribute to ischemic heart disease and atrial fibrillation (12), it has been suggested that FMF might promote atherogenesis secondary to a persisting inflammatory state (13). Various indirect markers of atherosclerosis have already been associated with diagnosis of FMF and include increased intima-media thickness (14), reduced vascular flow-mediated dilation (15) and reduced coronary flow reserve assessed by transthoracic Doppler echocardiography (16).

Recently, two electrocardiographic (ECG) indices have been reported to be altered in FMF patients: $\mathrm{P}$ wave dispersion (Pdisp), which reflects homogeneity of atrial conduction, and QT dispersion (QTdisp), is a measure which can indicate abnormalities of ventricular repolarization.

A prolonged Pdisp was described for adult FMF patients in Turkey (17), which is a known predictor for atrial fibrillation (AF) (18), one of the most common cardiac rhythmic disorders, and one associated with adverse outcomes (19).

Increased QTdisp (20) and a positive correlation of QTdisp with C-reactive protein (CRP) has also been described in Turkish FMF patients (21). Increased QTdisp is is reported to directly correlate with susceptibility to complex ventricular rhythm disorders and sudden cardiac death (22-24). ECG monitoring is cheap, non-invasive and widely available, and may provide an easy way to monitor for cardiac abnormalities.

It is known that for FMF the course of disease and clinical outcomes vary according to the country of residence, including for example, the prevalence of amyloidosis or the severity of disease $(25,26)$. Therefore, whilst studies describing electrocardiographic abnormalities in FMF patients living in countries where FMF is endemic exist, firstly they show conflicting results, and secondly, the results cannot be extrapolated to FMF patients from high prevalence that are resident in countries with low FMF prevalence. Currently, there are no studies describing ECG findings in adult FMF patients of Turkish ancestry living in Germany.

The aim of our study was therefore to compare Pdisp and QTdisp findings in FMF patients of Turkish descent living in Germany, with findings in a healthy control group in order to see whether it would make sense to include an ECG - screening into the routine workup of FMF patients.

\section{Method}

\section{Patients and controls}

Consecutive adult patients (age $\geq 18$ years) with FMF according to the simplified Livneh criteria (2) were prospectively included into the study at the University Medical Centre of the Ruhr-University Bochum, Herne. Patients reporting symptoms of an FMF attack within seven days prior to their presentation were excluded from the study. Age-matched healthy adults served as controls. All study participants were of Turkish ancestry. Informed consent was obtained prior to study inclusion. The study was approved by the ethics committee of the medical faculty of the Ruhr-University Bochum, Germany (study register number: 3772-10).

A structured interview and a clinical examination were performed by native Turkish speaking medical staff. Erythrocyte sedimentation rate (ESR), CRP and serum amyloid A (SAA) were assessed from blood or serum obtained at study inclusion. Disease severity in FMF patients was scored using the Pras et al. score (27).

\section{Electrocardiography}

A 12 - lead ECG was recorded during 5 seconds using a MAC 1200 ST (GE Medical systems information technology, GE, Providence, RI, USA) at a paper speed of $50 \mathrm{~mm} / \mathrm{sec}$ and a gain of $10 \mathrm{~mm}$ per $\mathrm{mV}$ with the patient lying supine. ECG electrodes were placed in the standard positions (28). During ECG recording patients were not speaking, but breathing freely. Two physicians experienced in the interpretation of ECG's and blinded to whether study participants were in the FMF patient or control groups performed the ECG measurements using calipers and a magnifying lens (10-fold magnification). Assessment of each measurement was repeated three times by each physician and the average value was used for analysis. Table 1 summarizes the definitions for the different measurements performed. We excluded patients in whom measurement of $\mathrm{P}$ wave or QT interval was not possible.

\section{Statistical analysis}

Statistical analyses were performed using SPSS (version 20.0; SPSS Inc. Chicago, IL, USA). Continuous variables are depicted as mean \pm standard deviation (SD), and compared using the Student $\mathrm{T}$ test. Categorical variables are depicted as number and percentage, and analysed using Fisher's exact test. Association between ECG measurements and biochemical markers of inflammation was assessed using Pearson's correlation coefficient. A two-tailed $p$ value 
less than 0.05 was considered statistically significant. Intra-class correlation coefficients were calculated to determine intra- and inter-rater reliability for ECG measurements.

Table I: Definition of ECG measurements

\begin{tabular}{l}
\hline ECG feature \\
\hline RR interval (RR) \\
P wave duration (P) \\
Minimum P wave duration \\
(Pmin) \\
Maximum P wave duration \\
(Pmax) \\
P wave dispersion (Pdisp) \\
QT interval (QT)
\end{tabular}

Minimum QT interval (QTmin) Maximum QT interval (QTmax) Corrected QT interval (cQT) QT interval dispersion (QTdisp)

\begin{abstract}
Definition used in our study
Duration between the peak of two

R-waves

Duration of the positive or negative wave between the first visible upward or downward deflection (depending on the waveform) from baseline and the subsequent return to baseline

Shortest $\mathrm{P}$ wave in all ECG leads

Longest $\mathrm{P}$ wave in all ECG leads

Difference between Pmin and Pmax

Duration between the first visible downward deflection from baseline after the end of the $P$ wave and the return to baseline after the $\mathrm{T}$ wave

Shortest QT interval in all ECG leads

Longest QT interval in all ECG leads

Difference between QTmin and QTmax

Rate correction of QT interval was performed with the use of the Bazett Formula (48) below:

$\mathrm{cQT}=\mathrm{QT} / \sqrt{\mathrm{RR}}$ in $\mathrm{s}$

Corrected intervals (cQTmin, cQTmax cQTdisp) were calculated in analogy.
\end{abstract}

\section{Results}

We enrolled 30 patients with FMF and 37 controls in the study and found the following ethnic characteristics: 13 patients $(43.3 \%)$ vs. $20(54.1 \%)$ controls were born in Turkey $(\mathrm{p}=0.464)$. Their age at immigration was $15.2 \pm 10.8$ vs. $12.4 \pm 8.5$ years respectively $(\mathrm{p}=0.412) .17 \mathrm{FMF}$ patients $(56.7 \%)$ and 17 controls $(45.9 \%)$ were born in Germany. Two of those FMF patients had one parent born in Turkey and one parent born in Germany (but of Turkish ancestry). The rest of the patients and all of the controls born in Germany had two parents that were born in Turkey.

The clinical and laboratory characteristics of the study participants are summarized in table 2 . None of the study participants had pre-existing diagnoses or symptoms of heart disease. Of the 30 patients with FMF, 26 were on regular prophylactic colchicine treatment. Of the remaining four patients, two had never taken colchicine, and two had discontinued the treatment earlier. Disease related characteristics of the patients with FMF are shown in table 3. ECG characteristics of the study participants are shown in table 4 . There was no significant correlation between Pdisp or QTdisp with any of the biochemical markers of inflammation (ESR, CRP, SAA; data not shown), and also Pdisp and QTdisp did not correlate with the Pras disease severity score (27) in patients with FMF patients.

As a subgroup analysis, we compared Pdisp, QTdisp and cQTdisp between the 26 FMF patients taking long-term colchicine and the 4 FMF patients who weren't. Secondly we analysed these two groups of FMF patients and healthy controls concerning Pdisp, QTdisp and cQTdisp. None of these comparisons yielded differences reaching statistical significance (data not shown).

For the longest QT interval (QT max) in all leads intra class correlation coefficient (ICC) was 0.93 for observer 1 and 0.94 for observer 2. ICC between the mean QTmax obtained by both observers was 0.99 .

Table 2: Clinical and laboratory characteristics of study participants

\begin{tabular}{llll}
\hline & $\begin{array}{l}\text { FMF patients } \\
(\mathbf{n}=\mathbf{3 0})\end{array}$ & $\begin{array}{l}\text { Controls } \\
(\mathbf{n}=\mathbf{3 7})\end{array}$ & Significance \\
\hline Female subjects n (\%) & $16(53.3)$ & $20(54.1)$ & $\mathrm{p}=1.00$ \\
Age (years) & $33.5 \pm 10.2$ & $33.7 \pm 10.6$ & $\mathrm{p}=0.94$ \\
Body length (cm) & $167.7 \pm 8.7$ & $169.0 \pm 11.1$ & $\mathrm{p}=0.62$ \\
Body weight $(\mathrm{kg})$ & $73.8 \pm 12.4$ & $78.7 \pm 18.9$ & $\mathrm{p}=0.21$ \\
Body mass index (BMI) & $26.2 \pm 3.9$ & $27.3 \pm 4.8$ & $\mathrm{p}=0.30$ \\
ESR (mm/1st hour), N: $<20$ & $23.7 \pm 14.3$ & $16.1 \pm 13.3$ & $\mathbf{p}=\mathbf{0 . 0 2 9}$ \\
CRP (mg/dl), N: $<0.5$ & $0.728 \pm 0.92$ & $0.262 \pm 0.41$ & $\mathbf{p}=\mathbf{0 . 0 1}$ \\
SAA (mg/dl), N: $<0.5$ & $3.14 \pm 4.82$ & $0.37 \pm 0.26$ & $\mathbf{p}<\mathbf{0 . 0 1}$ \\
\hline
\end{tabular}

n: number, p: significance; a p $<0.05$ is written in bold letters; ESR: erythrocyte sedimentation rate, CRP: C-reactive protein, SAA: serum amyloid A

Table 3: Disease related characteristics of FMF patients

\begin{tabular}{|c|c|c|c|c|}
\hline & $\begin{array}{l}\text { All FMF } \\
\text { patients } \\
(n=30)\end{array}$ & $\begin{array}{l}\text { FMF on } \\
\text { colchicine } \\
(n=26)\end{array}$ & $\begin{array}{l}\text { Significance } \\
\text { treated } \\
\text { vs. untreat- } \\
\text { ed }\end{array}$ & $\begin{array}{l}\text { FMF } \\
\text { without } \\
\text { colchicine } \\
(n=4)\end{array}$ \\
\hline Age (years) & $33.5 \pm 10.2$ & $32.3 \pm 10.3$ & $\mathrm{p}=0.09$ & $41.5 \pm 5.6$ \\
\hline Age at FMF onset (years) & $11.4 \pm 8.2$ & $10.4 \pm 6.7$ & $p=0.11$ & $17.5 \pm 14.7$ \\
\hline $\begin{array}{l}\text { Duration of disease } \\
\text { (years) }\end{array}$ & $21.7 \pm 9.3$ & $21.4 \pm 8.4$ & $\mathrm{p}=0.61$ & $24.0 \pm 15.4$ \\
\hline Pras score (27) & $6.93 \pm 2.00$ & $7.15 \pm 2.03$ & $\mathrm{p}=0.13$ & $5.5 \pm 1.00$ \\
\hline $\begin{array}{l}\text { Delay from disease onset } \\
\text { to initiation of colchicine } \\
\text { therapy (years) }\end{array}$ & $11.7 \pm 7.6$ & $11.7 \pm 7.6$ & n.a. & n.a. \\
\hline $\begin{array}{l}\text { Colchicine dosage } \\
\text { (mg/day) }\end{array}$ & $1.22 \pm 0.72$ & $1.40 \pm 0.57$ & n.a. & n.a. \\
\hline $\begin{array}{l}\text { ESR (mm/1 }{ }^{\text {st }} \text { hour), N: } \\
<20\end{array}$ & $23.7 \pm 14.3$ & $21.1 \pm 12.2$ & 0.008 & $40.8 \pm 16.8$ \\
\hline $\mathrm{CRP}(\mathrm{mg} / \mathrm{dl}), \mathrm{N}:<0.5$ & $0.73 \pm 0.92$ & $0.60 \pm 0.82$ & 0.042 & $1.59 \pm 1.19$ \\
\hline $\mathrm{SAA}(\mathrm{mg} / \mathrm{dl}), \mathrm{N}:<0.5$ & $3.14 \pm 4.82$ & $2.70 \pm 4.71$ & 0.220 & $6.40 \pm 5.24$ \\
\hline
\end{tabular}

n: number, p: significance; n.a.: not applicable; a $\mathrm{p}<0.05$ is written in bold letters. 
Table 4: Electrocardiographic characteristics of the study participants

\begin{tabular}{|c|c|c|c|}
\hline ECG feature & $\begin{array}{l}\text { FMF patients } \\
(\mathrm{n}=30)\end{array}$ & $\begin{array}{l}\text { Controls } \\
(\mathrm{n}=37)\end{array}$ & Significance \\
\hline RR (ms) & $814.4 \pm 150.2$ & $799.9 \pm 132.7$ & $p=0.68$ \\
\hline $\begin{array}{l}\text { Heart rate } \\
\text { (beats/minute) }\end{array}$ & $76.0 \pm 13.4$ & $77.1 \pm 13.1$ & $\mathrm{p}=0.74$ \\
\hline $\operatorname{Pmin}(\mathrm{ms})$ & $71.1 \pm 9.5$ & $66.4 \pm 11.7$ & $p=0.08$ \\
\hline $\operatorname{Pmax}(\mathrm{ms})$ & $114.7 \pm 10.7$ & $113.5 \pm 10.1$ & $p=0.63$ \\
\hline Pdisp (ms) & $43.7 \pm 11.9$ & $47.1 \pm 11.2$ & $p=0.23$ \\
\hline QTmin (ms) & $340.0 \pm 25.7$ & $335.1 \pm 24.5$ & $p=0.43$ \\
\hline cQTmin (ms) & $379.5 \pm 24.3$ & $377.4 \pm 29.8$ & $\mathrm{p}=0.75$ \\
\hline QTmax (ms) & $405.9 \pm 23.5$ & $402.7 \pm 24.7$ & $p=0.59$ \\
\hline cQTmax (ms) & $453.4 \pm 24.8$ & $453.4 \pm 28.9$ & $p=0.99$ \\
\hline QTdisp (ms) & $65.9 \pm 12.3$ & $67.6 \pm 12.7$ & $p=0.58$ \\
\hline cQTdisp (ms) & $73.9 \pm 15.0$ & $76.0 \pm 13.3$ & $p=0.55$ \\
\hline
\end{tabular}

The abbreviations for the ECG features are described in table 1. n: number, a $\mathrm{p}<0.05$ is written in bold letters, ms: milliseconds.

\section{Discussion}

Our study assesses markers of cardiac involvement in FMF patients living in Germany. No differences in Pdisp, QTdisp and cQTdisp were found between FMF patients and controls. We also did not find a significant correlation between Pdisp or QTdisp and any of the biochemical markers of inflammation studied.

Our data concerning homogeneity of atrial conduction, or Pdisp, in patients and controls are in line with two previous studies $(29,30)$, though two other studies do report an association between CRP and Pdisp, $(17,31)$, as shown summarized in Table 5. In the literature there is evidence for a link between inflammation and an elevated Pdisp from hypertensive patients with arterial hypertension $(32,33)$, while an elevated Pdisp can also be a predictor of atrial fibrillation (18). Data from a long-term follow up of FMF patients concerning the occurrence of atrial arrhythmias is lacking so far. An additional explanation for the varying results might be Pdisp varies even within healthy subjects depending on the method of measurement and the population chosen. However, the method chosen in our study is the best available.

We also found no difference in QTdisp or cQTdisp between patients with FMF and controls, though literature regarding these indices are also conflicting. Table 6 summarises the studies supporting (34-37) and opposing our findings $(20,21)$.

Different inflammatory rheumatic diseases are known to increase QTdisp including rheumatoid arthritis (cQTdisp patients: $40.2 \pm 14.4$ ms vs. controls: $23.8 \pm 6.1 \mathrm{~ms}$ ) (38), ankylosing spondylitis (cQTdisp patients: $60.3 \pm 16.1 \mathrm{~ms}$ vs. controls: $39.4 \pm 10.7 \mathrm{~ms})$ (39) and systemic lupus erythematosus (QTdisp patients: $55.2 \pm 24.7 \mathrm{~ms}$ vs. controls: $20.7 \pm 5.3 \mathrm{~ms})(40)$.

So far, ECG measurements of atrial conduction and cardiac repolarization have not been proven to be useful as indirect markers of cardiovascular involvement in identifying increased risk of atrial or ventricular arrhythmias, in patients with FMF. Only two studies have evaluated the long-term outcome of FMF patients since colchicine became an accepted treatment. A cohort of over 1.2 million Israeli army recruits followed for more than 20 years showed an increased mortality in FMF patients compared to controls, with renal amyloidosis responsible for death in $40 \%$ of FMF patients (41). In another cohort study from Turkey, amyloidosis was responsible for $50 \%$ of deaths among FMF patients during a median follow-up time of 6 years, and amyloidosis was the only independent predictor of mortality (42). Colchicine has been proven to be useful in the secondary prophylaxis of vascular events in patients with coronary heart disease (43), atrial fibrillation (44) as well as in the prevention of in-stent restenosis in diabetic patients (45). One might therefore speculate that colchicine, which is currently prescribed to most FMF patients, may antagonize some of the detrimental effects of chronic inflammation - as they are known for other inflammatory diseases - on the cardiovascular system.

Table 5: Summary of studies evaluating $P$ wave dispersion in FMF patients

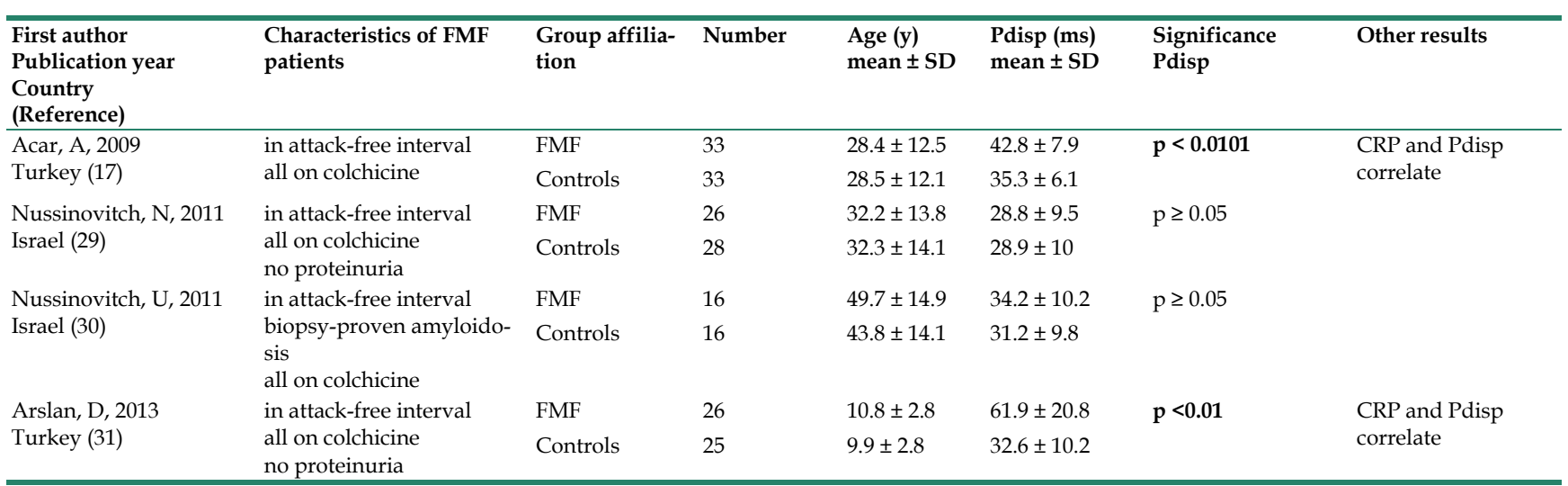

ms: milliseconds; a $\mathrm{p}<0.05$ is written in bold letters; the abbreviations for the ECG features are described in table 1. 
Table 6: Summary of studies evaluating QT wave dispersion in FMF patients

\begin{tabular}{|c|c|c|c|c|c|c|c|}
\hline $\begin{array}{l}\text { First author } \\
\text { Publication year } \\
\text { Country } \\
\text { (Reference) }\end{array}$ & Characteristics of FMF patients & $\begin{array}{l}\text { Group } \\
\text { affiliation }\end{array}$ & Number & $\begin{array}{l}\text { Age } \\
\text { mean } \pm S D\end{array}$ & $\begin{array}{l}\text { cQTdisp }(\mathrm{ms}) \\
\text { mean } \pm S D\end{array}$ & $\begin{array}{l}\text { Significance } \\
\text { cQTdisp }\end{array}$ & Other results \\
\hline \multirow{2}{*}{$\begin{array}{l}\text { Akcay, A, } 2009 \\
\text { Turkey (21) }\end{array}$} & \multirow{2}{*}{ in attack-free interval } & FMF & 50 & $29.4 \pm 11.8$ & $40.4 \pm 13.5$ & \multirow[t]{2}{*}{$\mathrm{p}<0.01$} & \multirow{6}{*}{$\begin{array}{l}\text { cQTdisp correlates } \\
\text { with CRP and ESR }\end{array}$} \\
\hline & & Controls & 50 & $31.3 \pm 11.9$ & $21.9 \pm 12.4$ & & \\
\hline \multirow{2}{*}{$\begin{array}{l}\text { Nussinovitch, N, } 2010 \\
\text { Israel (35) }\end{array}$} & \multirow{2}{*}{$\begin{array}{l}\text { in attack-free interval } \\
\text { all on colchicine } \\
\text { no amyloidosis }\end{array}$} & FMF & 32 & $35.3 \pm 16.9$ & $51.4 \pm 12.0$ & \multirow[t]{2}{*}{$\mathrm{p} \geq 0.05$} & \\
\hline & & Controls & 37 & $34 \pm 13.7$ & $49.7 \pm 10.5$ & & \\
\hline \multirow{2}{*}{$\begin{array}{l}\text { Topal, F, } 2011 \\
\text { Turkey (36) }\end{array}$} & \multirow[t]{2}{*}{ in attack-free interval } & FMF & 38 & $32.8 \pm 11.0$ & $33.6 \pm 15$ & \multirow[t]{2}{*}{$\mathrm{p} \geq 0.05$} & \\
\hline & & Controls & 35 & $28.1 \pm 9.1$ & $35.5 \pm 19.2$ & & \\
\hline \multirow{2}{*}{$\begin{array}{l}\text { Canpolat, U, } 2012 \\
\text { Turkey (20) }\end{array}$} & \multirow{2}{*}{$\begin{array}{l}\text { in attack-free interval } \\
\text { all on colchicine } \\
\text { no amyloidosis }\end{array}$} & FMF & 38 & $34.4 \pm 10.2$ & $76.6 \pm 12.6$ & \multirow[t]{2}{*}{$\mathrm{p}<0.01$} & \multirow{8}{*}{$\begin{array}{l}\text { QTdisp correlates } \\
\text { with disease dura- } \\
\text { tion and CRP }\end{array}$} \\
\hline & & Controls & 34 & $33.2 \pm 9.3$ & $52.4 \pm 11.7$ & & \\
\hline \multirow{2}{*}{$\begin{array}{l}\text { Koca, B, } 2012 \\
\text { Turkey (37) }\end{array}$} & \multirow[t]{2}{*}{ children with FMF } & FMF & 69 & $10.8 \pm 2.9$ & $64 \pm 21.4$ & \multirow[t]{2}{*}{$p=0.26$} & \\
\hline & & Controls & 71 & $9.9 \pm 2.8$ & $59.7 \pm 24$ & & \\
\hline \multirow{2}{*}{$\begin{array}{l}\text { Nussinovitch, U, } 2012 \\
\text { Israel (34) }\end{array}$} & \multirow{2}{*}{$\begin{array}{l}\text { in attack-free interval } \\
\text { all on colchicine but } \\
\text { non-responsive to colchicine } \\
\text { no proteinuria }\end{array}$} & FMF & 22 & $36.3 \pm 10.5$ & $46.0 \pm 13.5$ & \multirow[t]{2}{*}{$\mathrm{p} \geq 0.05$} & \\
\hline & & Controls & 22 & $34.0 \pm 13.1$ & $45.3 \pm 7.9$ & & \\
\hline \multirow{2}{*}{$\begin{array}{l}\text { Nussinovitch, U, } 2012 \\
\text { Israel (49) }\end{array}$} & \multirow{2}{*}{$\begin{array}{l}\text { in attack-free interval } \\
\text { biopsy-proven amyloidosis } \\
\text { all on colchicine }\end{array}$} & FMF & 18 & $50.2 \pm 14.2$ & $40.6 \pm 16.4$ & \multirow[t]{2}{*}{$\mathrm{p} \geq 0.05$} & \\
\hline & & Controls & 18 & $44.0 \pm 13.9$ & $40.7 \pm 13.2$ & & \\
\hline
\end{tabular}

ms: milliseconds; a $\mathrm{p}<0.05$ is written in bold letters; the abbreviations for the ECG features are described in table 1.

\section{Study limitations}

Although reliable data on the prevalence of FMF in Germany are lacking FMF is thought to be a rare disease in Germany. The incidence among children $\leq$ 16 years is estimated to range between 25-50 newly diagnosed FMF cases per year leading to a number of about 400 to 800 affected children $\leq 16$ years $(300-600$ of them with a Turkish ancestry) (46). The size of our study thus results from the scarcity of FMF patients in Germany.

Previous studies dealing with electrocardiographic markers in FMF included only patients on regular colchicine treatment. In the present study 4 of the 30 FMF patients $(13,3 \%)$ were not regularly taking colchicine at the time of study inclusion. The subgroup of FMF patients not regularly taking colchicine show no difference in Pdisp or QTdisp. However, it is too small $(n=4)$ to exclude a difference with sufficient power.

Our study did not include echocardiographic assessment of study participants. We could thus not verify the findings of previous studies dealing with atrial conduction in FMF. Inter-atrial and intra-atrial electromechanical delay (measured as the time from the onset of the P wave on surface ECG to the beginning of the A wave on tissue Doppler echocardiography) has been reported to be prolonged in FMF patients compared to healthy controls (17) and some echocardiographic markers of diastolic function might be altered in FMF patients (31). Of all the studies dealing with ventricular repolarisation in FMF only two included an electrocardiographic assessment showing no significant difference between patients and controls $(21,37)$.

In the present study the diagnosis of FMF was confirmed among patients using the simplified Livneh criteria. These criteria have been reported to yield a sensitivity and specificity $\geq 96 \%$ (2). FMF was also clinically excluded among controls. A routine genetic assessment of the MEFV Gene was not part of the study. Thus genetic data was only available for some FMF patients and for none of the controls. Since the proportion of people heterozygous for one of the MEFV mutations typical for FMF among Turkish people might be as high as $20 \%$ (47) we cannot exclude the presence of MEFV heterozygotes among the controls.

Future work of interest would be a multicentre study to augment sample size and minimize selection bias as well as a long-term study centered on cardiovascular involvement of FMF. Further studies should also include an echocardiographic assessment and a screening of the MEFV - gene in patients and controls to evaluate other cardiovascular markers und to assess the importance of the MEFV genotype.

\section{Conclusion}

As an autoinflammatory disease FMF is associated with a persisting inflammatory state. Since atherosclerosis and cardiovascular events have been linked to inflammation the question is whether FMF patients are prone to a higher cardiovascular risk. So far this has not been studied in a country with a low prevalence of FMF. 
In our study on FMF patients and healthy controls living in Germany we have examined two ECG markers that are increased in cardiac atrial or ventricular rhythmic disorders: Pdisp and QTdisp. We have found no association of FMF with Pdisp or QTdisp. Furthermore there was no correlation of Pdisp or QTdisp with biochemical markers of inflammation.

The absence of an association between FMF and Pdisp or QTdisp as markers of cardiac arrhythmias found in our study is in line with reports on the long-term prognosis of FMF patients. These reports indicate that renal amyloidosis but not coronary heart disease is the only significant predictor of mortality.

Since data on ECG indices in FMF are conflicting future studies will have to further elucidate the relationship between cardiovascular disease and autoinflammation.

\section{Acknowledgements}

We are indebted to Dr. Atilla Cintosun, Herne for his assistance in patient recruitment.

\section{Conflict of interest}

There are no financial or other relationships that could lead to a conflict of interest.

\section{References}

1. Ben-Chetrit E, Levy M. Familial Mediterranean fever. Lancet. [Review]. 1998 199802 28;351:659- 64

2. Livneh A, Langevitz P, Zemer D, Zaks N, Kees S, Lidar T, et al. Criteria for the Diagnosis of Familial Mediterranean Fever. Arthritis Rheum. [Original Article]. 1997 1997 10;40(10):1879-85

3. Consortium TIF. Ancient Missense Mutations in a New Member of the RoRet Gene Family Are Likely to Cause Familial Mediterranean Fever. Cell. [Original Article]. 1997199708 22;90:797-807.

4. Consortium FF. A candidate gene for familial Mediterranean fever. Nat Genet. [Original Article]. 19971997 09;17(1):25-31.

5. Kallinich T, Haffner D, Niehues T, Huss K, Lainka E, Neudorf U, et al. Colchicine Use in Children and Adolescents With Familial Mediterranean Fever: Literature Review and Consensus Statement. Pediatrics. [Review]. 2007 2007 01 22;119:e474-e83.

6. Hentgen V, Grateau G, Kone-Paut I, Livneh A, Padeh S, Rozenbaum M, et al. Evidence-based recommendations for the practical management of Familial Mediterranean Fever. Semin Arthritis Rheum. 2013 Jun 3;43(3):387-91.

7. Goldstein R, Schwabe A. Prophylactic colchicine therapy in familial Mediterranean fever. A controlled, double-blind study. Ann Intern Med. [Original Article]. 19741974 12;81(6):792-4.

8. Dinarello C, Wolff S, Goldfinger S, Dale D, Alling D. Colchicine therapy for familial mediterranean fever. A double-blind trial. N Engl J Med. [Original Article]. 1974197410 31;291(18):934-7.

9. Goldfinger S. Colchicine for familial Mediterranean fever. N Engl J Med. 1972 197212 21;287(25):1302.

10. Zemer D, Pras M, Sohar E, Modan M, Cabili S, Gafni J. Colchicine in the prevention and treatment of the amyloidosis of familial Mediterranean fever. N Engl J Med. [Original Article]. 1986198604 17;314(16):1001-5.

11. Lachmann HJ, Sengul B, Yavuzsen TU, Booth DR, Booth SE, Bybee A, et al. Clinical and subclinical inflammation in patients with familial Mediterranean fever and in heterozygous carriers of MEFV mutations. Rheumatology (Oxford). 2006 Jun;45(6):746-50.

12. Boos CJ, Anderson RA, Lip GY. Is atrial fibrillation an inflammatory disorder? Eur Heart J. 2006 Jan;27(2):136-49.

13. Yuksel S, Ayvazyan L, Gasparyan AY. Familial mediterranean Fever as an emerging clinical model of atherogenesis associated with low-grade inflammation. Open Cardiovasc Med J. 2010;4:51-6.

14. Bilginer Y, Ozaltin F, Basaran C, Duzova A, Besbas N, Topaloglu R, et al. Evaluation of intima media thickness of the common and internal carotid arteries with inflammatory markers in familial Mediterranean fever as possible predictors for atherosclerosis. Rheumatol Int. 2008 Oct;28(12):1211-6.
15. Akdogan A, Calguneri M, Yavuz B, Arslan EB, Kalyoncu U, Sahiner L, et al. Are familial Mediterranean fever (FMF) patients at increased risk for atherosclerosis? Impaired endothelial function and increased intima media thickness are found in FMF. J Am Coll Cardiol. 2006 Dec 5;48(11):2351-3.

16. Caliskan M, Gullu H, Yilmaz S, Erdogan D, Unler GK, Ciftci O, et al. Impaired coronary microvascular function in familial Mediterranean fever. Atherosclerosis. 2007 Dec;195(2):e161-7.

17. Acar G, Akcay A, Sayarlioglu M, Sokmen A, Sokmen G, Koroglu S, et al. Assessment of atrial conduction time in patients with familial Mediterranean fever. Pacing Clin Electrophysiol. 2009 Mar;32(3):308-13.

18. Aytemir K, Ozer N, Atalar E, Sade E, Aksoyek S, Ovunc K, et al. P wave dispersion on 12-lead electrocardiography in patients with paroxysmal atrial fibrillation. Pacing Clin Electrophysiol. 2000 Jul;23(7):1109-12.

19. Brand FN, Abbott RD, Kannel WB, Wolf PA. Characteristics and prognosis of lone atrial fibrillation. 30-year follow-up in the Framingham Study. JAMA. 1985 Dec 27;254(24):3449-53.

20. Canpolat U, Dural M, Aytemir K, Akdogan A, Kaya EB, Sahiner L, et al. Evaluation of various cardiac autonomic indices in patients with familial Mediterranean fever on colchicine treatment. Auton Neurosci. 2012 Apr 3;167(1-2):70-4.

21. Akcay A, Acar G, Sayarlioglu M, Sokmen A, Kaya H, Ispiroglu M, et al. QT dispersion and transmural dispersion of repolarization in patients with familial Mediterranean fever. Mod Rheumatol. 2009;19(5):550-5.

22. Kuo CS, Munakata K, Reddy CP, Surawicz B. Characteristics and possible mechanism of ventricular arrhythmia dependent on the dispersion of action potential durations. Circulation. 1983 Jun;67(6):1356-67.

23. Fei L, Statters DJ, Camm AJ. QT-interval dispersion on 12-lead electrocardiogram in normal subjects: its reproducibility and relation to the $\mathrm{T}$ wave. Am Heart J. 1994 Jun;127(6):1654-5.

24. Higham PD, Campbell RW. QT dispersion. Br Heart J. 1994 Jun;71(6):508-10.

25. Touitou I, Sarkisian T, Medlej-Hashim M, Tunca M, Livneh A, Cattan D, et al. Country as the primary risk factor for renal amyloidosis in familial Mediterranean fever. Arthritis Rheum. [Original Article]. 20072007 05;56(5):1706 - 12.

26. Ozen S, Aktay N, Lainka E, Duzova A, Bakkaloglu A, Kallinich T. Disease severity in children and adolescents with familial Mediterranean fever: a comparative study to explore environmental effects on a monogenic disease. Ann Rheum Dis. [Original Article]. 2008200809 18;68:246 - 8.

27. Pras E, Livneh A, Balow JE, Jr., Kastner DL, Pras M, Langevitz P. Clinical differences between North African and Iraqi Jews with familial Mediterranean fever. Am J Med Genet. 1998 Jan 13;75(2):216-9.

28. Kligfield P, Gettes LS, Bailey JJ, Childers R, Deal BJ, Hancock EW, et al. Recommendations for the standardization and interpretation of the electrocardiogram: part I: the electrocardiogram and its technology a scientific statement from the American Heart Association Electrocardiography and Arrhythmias Committee, Council on Clinical Cardiology; the American College of Cardiology Foundation; and the Heart Rhythm Society endorsed by the International Society for Computerized Electrocardiology. J Am Coll Cardiol. 2007 Mar 13;49(10):1109-27.

29. Nussinovitch N, Livneh A, Katz K, Nussinovitch M, Volovitz B, Lidar M, et al. $\mathrm{P}$ wave dispersion in familial Mediterranean fever. Rheumatol Int. 2011 Dec;31(12):1591-4.

30. Nussinovitch U, Livneh A, Nussinovitch M, Volovitz B, Ben-Zvi I, Lidar M, et al. P-wave dispersion in systemic AA amyloidosis of familial Mediterranean fever. Clin Rheumatol. 2011 Oct;30(10):1295-8.

31. Arslan D, Oran B, Yazilitas F, Peru H, Cimen D, Vatansev H. P-wave duration and dispersion in children with uncomplicated familial Mediterranean fever. Mod Rheumatol. 2013 Nov;23(6):1166-71.

32. Mazza A, Bendini MG, Cristofori M, Leggio M, Nardi S, Giordano A, et al. $\mathrm{C}$-reactive protein and $\mathrm{P}$-wave in hypertensive patients after conversion of atrial fibrillation. J Cardiovasc Med (Hagerstown). 2013 Jul;14(7):520-7.

33. Tsioufis C, Syrseloudis D, Hatziyianni A, Tzamou V, Andrikou I, Tolis P, et al. Relationships of CRP and $\mathrm{P}$ wave dispersion with atrial fibrillation in hypertensive subjects. Am J Hypertens. 2010 Feb;23(2):202-7.

34. Nussinovitch U, Livneh A, Volovitz B, Nussinovitch M, Ben-Zvi I, Lidar M, et al. Normal QT dispersion in colchicine-resistant familial Mediterranean fever (FMF). Clin Rheumatol. 2012 Jul;31(7):1093-6

35. Nussinovitch N, Livneh A, Katz K, Langevitz P, Feld O, Nussinovitch M, et al. QT dispersion in uncomplicated familial Mediterranean fever. Clin Rheumatol. 2010 Dec;29(12):1353-6.

36. Topal F, Tanindi A, Kurtoglu HG, Akbulut S, Kucukazman M, Topal FE. QT dispersion is not increased in familial Mediterranean fever. J Int Med Res. 2011;39(5):2006-11.

37. Koca B, Kasapcopur O, Bakari S, Sonmez E, Oztunc F, Eroglu AG, et al. QT dispersion and cardiac involvement in children with Familial Mediterranean fever. Cardiol Young. 2012 Aug;22(4):404-9.

38. Cindas A, Gokce-Kutsal Y, Tokgozoglu L, Karanfil A. QT dispersion and cardiac involvement in patients with rheumatoid arthritis. Scand J Rheumatol. 2002;31(1):22-6.

39. Yildirir A, Aksoyek S, Calguneri M, Aytemir K, Kabakci G, Ovunc K, et al. QT dispersion as a predictor of arrhythmic events in patients with ankylosing spondylitis. Rheumatology (Oxford). 2000 Aug;39(8):875-9.

40. Yavuz B, Atalar E, Karadag O, Tulumen E, Ozer N, Akdogan A, et al. QT dispersion increases in patients with systemic lupus erythematosus. Clin Rheumatol. 2007 Mar;26(3):376-9. 
41. Twig G, Livneh A, Vivante A, Afek A, Shamiss A, Derazne E, et al. Mortality risk factors associated with familial Mediterranean fever among a cohort of 1.25 million adolescents. Ann Rheum Dis. 2013 Mar 16;Epub ahead of print.

42. Akar S, Yuksel F, Tunca M, Soysal O, Solmaz D, Gerdan V, et al. Familial Mediterranean fever: risk factors, causes of death, and prognosis in the colchicine era. Medicine (Baltimore). 2012 May;91(3):131-6.

43. Nidorf SM, Eikelboom JW, Budgeon CA, Thompson PL. Low-dose colchicine for secondary prevention of cardiovascular disease. J Am Coll Cardiol. 2013 Jan 29;61(4):404-10.

44. Deftereos S, Giannopoulos G, Kossyvakis C, Efremidis M, Panagopoulou V, Kaoukis A, et al. Colchicine for prevention of early atrial fibrillation recurrence after pulmonary vein isolation: a randomized controlled study. J Am Coll Cardiol. 2012 Oct 30;60(18):1790-6.

45. Deftereos S, Giannopoulos $G$, Raisakis $K$, Kossyvakis $C$ Kaoukis A Panagopoulou V, et al. Colchicine treatment for the prevention of bare-metal stent restenosis in diabetic patients. J Am Coll Cardiol. 2013 Apr 23;61(16):1679-85.

46. Lainka E, Bielak M, Lohse P, Timmann C, Stojanov S, von Kries R, et al. Familial Mediterranean fever in Germany: epidemiological, clinical, and genetic characteristics of a pediatric population. Eur J Pediatr. 2012 Dec;171(12):1775-85.

47. Papadopoulos V, Giaglis S, Mitroulis I, Ritis K. The Population Genetics of Familial Mediterranean Fever: A Meta-Analysis Study. Ann Hum Genet. [Original Article]. 2008 2008;72:752-61.

48. Bazett $H$. An analysis of the time relations of electrocardiograms. Heart. 1920;7:353-55.

49. Nussinovitch U, Nussinovitch N, Nussinovitch M, Volovitz B, Feld O, Ben-Zvi $\mathrm{I}$, et al. QT dispersion in amyloidosis due to familial Mediterranean fever. Rheumatol Int. 2012 Jul;32(7):1945-8. 